\title{
ELECTRONIC DOCUMENT MANAGEMENT: A HUMAN RESOURCE MANAGEMENT CASE STUDY
}

\author{
THOMAS GROENEWALD \\ Programme in Leadership in Performance and Change \\ Department of Human Resource Management \\ Rand Afrikaans University \\ tgroenew@tsa.ac.za
}

\begin{abstract}
This case study serve as exemplar regarding what can go wrong with the implementation of an electronic document management system. Knowledge agility and knowledge as capital, is outlined against the backdrop of the information society and knowledge economy. The importance of electronic document management and control is sketched thereafter. The literature review is concluded with the impact of human resource management on knowledge agility, which includes references to the learning organisation and complexity theory. The intervention methodology, comprising three phases, follows next. The results of the three phases are presented thereafter. Partial success has been achieved with improving the human efficacy of electronic document management, however the client opted to discontinue the system in use.
\end{abstract}

\section{OPSOMMING}

Die gevalle studie dien as voorbeeld van kan verkeerd wat loop met die implementering van 'n elektroniese dokumentbestuur sisteem. Teen die agtergrond van die inligtingsgemeenskap en kennishuishouding word kennissoepelheid en kennis as kapitaal bespreek. Die literatuurstudie word afgesluit met die inpak van menslikehulpbronbestuur op kennissoepelheid, wat ook die verwysings na die leerorganisasie en kompleksietydsteorie insluit. Die metodologie van die intervensie, wat uit drie fases bestaan, volg daarna. Die resultate van die drie fases word vervolgens aangebied. Slegs gedeelte welslae is behaal met die verbetering van die menslike doeltreffendheid ten opsigte van elektroniese dokumentbestuur. Die klient besluit egter om nie voort te gaan om die huidige sisteem te gebruik nie.

\begin{abstract}
"Unlike other forms of capital - land, equipment, labor and money $-\ldots$ [t]here is always a new idea waiting to be discovered - new ways of doing things, new products, new strategies, new markets" (McElroy, 2000, p. 195). Because knowledge is theoretically infinite, the aim is to get to the next important discovery first. According to Karamuftuoglu (1999), the knowledge-based economy, alternatively called innovation economy or information society, heralds the start of a period where humans will be liberated from mundane and often dangerous work. The knowledge-based economy will enable humans to channel their potential to more creative and challenging tasks.
\end{abstract}

Knowledge is the 'capital' of the global information society. The knowledge economy is an emergent reality, because no nation can any longer depend on its ability to acquire and convert raw materials (Laszlo \& Laszlo, 2002; Mehra, 2001). Megill (1997) states that in the electronic age, information is an asset that must be managed like all other assets. Information is created, stored, kept and used; it can be sold and traded; and it can be used and reused. When other assets are used for a specific purpose it can usually not be used for another. "Information, however, is different. Shared information is not lost. In fact, when information is shared and put into context, it often gains value for the creator as well as for the person with whom it is shared. Information is not only not a depletable resource, it is one that grows and thrives with use" (p. 2). Information grows and prospers in an environment in which it is shared, used and reused.

The better an organisation is able to share its information, the more valuable that information becomes. Knowledge has emerged as a critical factor in controlling the global economy (Laszlo \& Laszlo, 2002; Mehra, 2001). The significance of knowledge creation, learning, and innovation to the knowledge economy therefore cannot be underestimated.

With the drastic increase in electronic documentation, an electronic document management system with reliable storage

Requests for copies should be addressed to: T Groenewald, Department of Human Resource Management, RAU University, PO Box 524, Auckland Park, 2006 and backup procedures is essential. The potential weak link is the human element and therefore a burning people management issue.

According to McElroy (2000, p. 195) "corporate knowledge is now being viewed as the last and only sustainable untapped source of competitive advantage in business". Alternative terms to corporate knowledge include intellectual capital, intellectual property, knowledge assets, or business intelligence. In this regard Dove $(1999$, p. 1) postulates that "new knowledge has no value until it is applied", and when it is, it introduces change into the environment, which generates value. Within the context of corporate knowledge as competitive advantage Dove (1999), Meredith and Francis (2000) and Vernadat (1999) propose the term 'agility', for example an 'agile enterprise' or 'agile manufacturing'. Dove associates the word agile with cats - both physically adept at movement and also mentally adept at choosing the appropriate movement in a given situation. Vernadat (1999, p. 37) defines agility as "the ability to closely align enterprise systems to changing business needs in order to achieve competitive performance". Meredith and Francis (2000) support this definition by stating that in order to retain a competitive advantage, an enterprise needs to be aware of, and creatively respond to many elements within the competitive environment. Similar to Vernadat's definition, Dove regards organisational agility as the ability of an organisation to thrive in a continuously and unpredictably changing environment. As a result of the escalating pace of knowledge development and the concomitant knowledge-value decay, organisations need to develop competence in knowledge agility. An over emphasis on knowledge management results in an organisational state of 'muscular rigidity'. An overemphasis on the ability to respond results in involuntary sudden and violent organisational 'muscular contractions' or sudden convulsive movements. Kraak (2000) also highlights the paradoxical state of networking or co-operation on the one hand and competition on the other. This striving to achieve a fine balance is illustrated in Figure 1. 


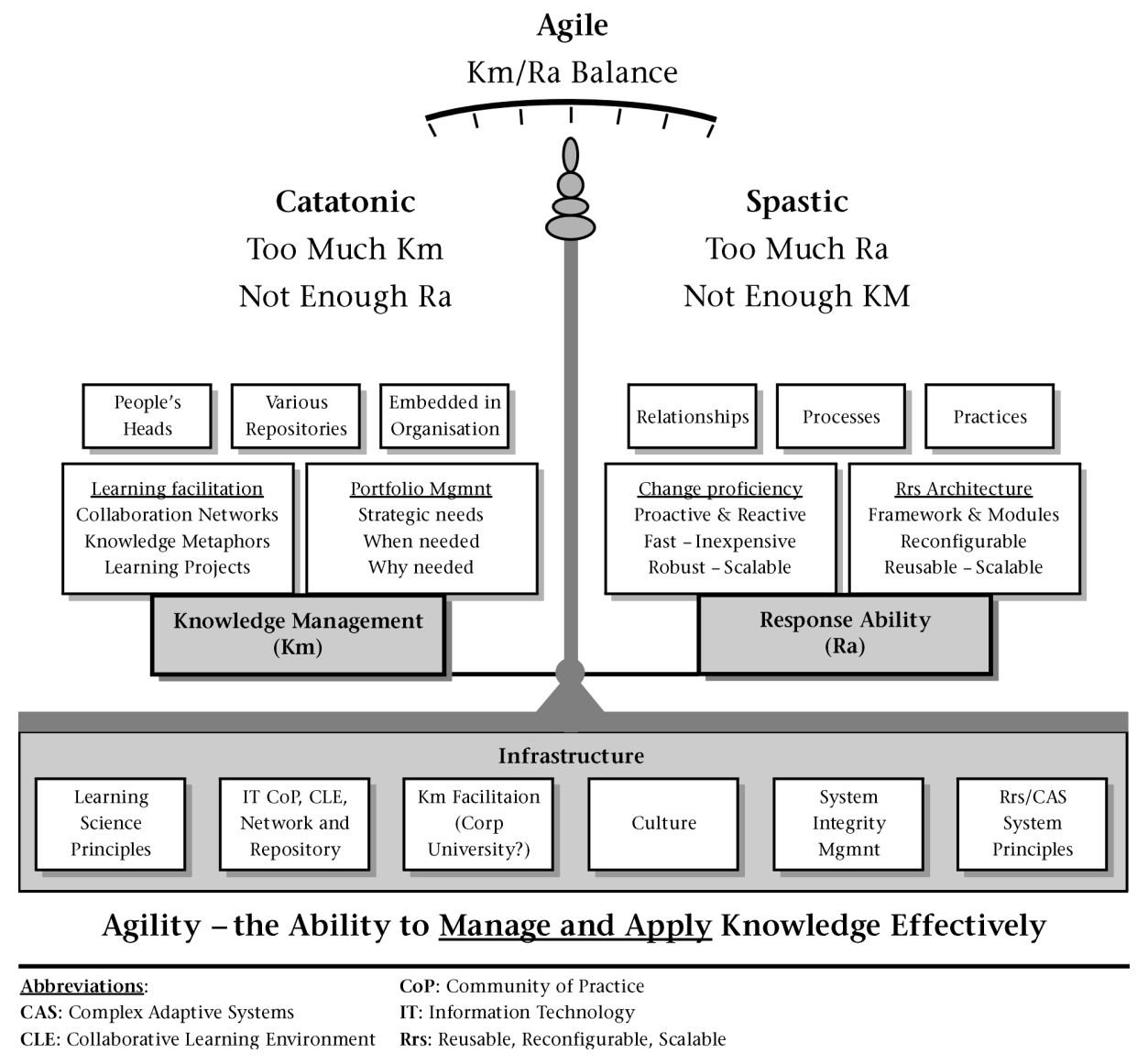

Figure 1: Agility = knowledge management + response ability (Dove, 1999, p. 2).

Knowledge has been found to be a substantial influential factor with regard to the accelerated pace and magnitude of economic growth (Mehra, 2001). Consequently, the concept of knowledge sharing and the use of knowledge have changed. Knowledge is preserved as capital and transformed by entrepreneurs into income and wealth. Knowledge remains capital as long as it remains the property of either an individual or an organisation. Karamuftuoglu (1999) highlights a number of key characteristics of knowledge:

- once produced it can easily be reproduced and transmitted at low cost:

- it can never be consumed or depleted;

- to maintain a monopoly of knowledge is extremely difficult and knowledge tends to flow into the public domain; and

- therefore knowledge only retains an exchange value (price) as long as it is protected by, for example, copyright or patents.

To remain competitive, an organisation needs to continuously develop new knowledge. The smallest unit of knowledge generation (according to Mehra, 2001) is the individual. He therefore concludes that knowledge resides as human capital.

Against the preceding background of the electronic age, the knowledge-based economy, the importance of knowledge agility and the need for continuous knowledge development, the key aspects of electronic document management systems (EDMS) are next presented.

Electronic document management and control

The purpose of EDMS is to manage and control all electronic documentation - whether word processing documents, spreadsheets, presentations, graphics or e-mail messages through their life cycle. It enables an organisation to ensure the availability of information wherever it is needed. It also ensures the security of electronic documents through version control, audit trails for each document, and by controlling access to documents via various security levels.
EDMS manage and control all unstructured information that is, information in for example word processing documents, presentation packages, spreadsheets, e-mail, graphics - in one single database accessible through a single interface. It gives companies the ability to ensure the availability of information whenever it is needed and ensures document integrity. It further avoids or limits duplication of effort already undertaken. Just as there are standard procedures to manage and control paper documents and records, suitable procedures should be implemented to manage electronic documents throughout their life cycle. The control offered by an EDMS also ensures document integrity. Document integrity includes the ability to identify and access records over time, as well as ensuring that the document is the authentic master copy/authoritative version. A document has integrity when it can be shown that the document has not changed, without going through the proper channels. This is very difficult to do where electronic files are concerned. It is easy to open a file and change it without anyone knowing. With an EDMS, document integrity will be ensured, since audit trails can be used as proof that a document is still the authorised copy; security will ensure that no unauthorised access can take place; and version control will ensure that the latest, most current or approved version will be easy to identify. Without document management, it will be difficult to prove the integrity of an electronic document, should a legal need arise. If the actual electronic document is controlled and can be shown to be controlled, document integrity can be ensured more easily.

There are numerous EDMS packages on the market. Some scanning and storage software packages are marketed as an EDMS. Although real EDMS differ in the way they are structured and operate, they usually have in common the functionalities given in Table 1. 
TABLE 1

The functionalities of Electronic Document Management Systems

\begin{tabular}{lll}
\hline DOMAIN & FUNCTIONALITY & ELEMENTS/DESCRIPTION \\
\hline Manage & $\begin{array}{ll}\text { Managing the life cycle of documents from creation to sharing, } \\
\text { distribution, storing and archiving or disposal. }\end{array}$ & - the document is created on the system. \\
& - stored on the system. \\
& - accessed through the system. \\
& - shared via the system. \\
& - archived according to specified retention schedules. \\
& some systems also allow relationships to other documents to be \\
& created and shown.
\end{tabular}

Check-in/check-out.

Off-line options.

Control

Security

Version/revision control.

Audit trails.

Identification and retrieval
Metadata - system and customised capturing of metadata.

Retrieval - basic and advanced search functionalities. (documents are 'checked-out' while they are being edited so that only one person at a time can work on a document).

- For files to be exported to laptops, stiffies, memory sticks, modified, and checked back in to the system.

- Some systems will allow the user to keep working on open documents when the system goes down for some reason, and prompt to synchronise the off-line copy with the on-line copy when the system is back on-line.

- Control access to the system.

- Control access to the documents.

- Various types of access to documents (view profile, read only, modify, change security).

(the history of the document).

(System metadata are captured automatically by the system and would include date created/modified, application, location. These data can usually not be modified. Customised metadata are captured by the originator, and can include anything the company finds most useful in retrieving documentation, e.g. document type, division, technical order/project number, file number, client.)

Most systems also allow the user to save searches so that they can be rerun with one click.

Indexing - metadata and usually full text of the documents are indexed for searching.

Regarding retrieval and version control McCready \& Murray (n.d., p. 10) emphasise the time value of money and use the phrase 'waiting is not free' with regard to locating existing documents. They also highlight the need for 'streamlining the review and approval process' (p. 11) and the importance of 'ensuring that everyone is working with the latest' version (p. 12). White (2001, p. 2) shares a horrifying experience:

I have many times come across the situation where the people on the ground actually building a plant or fabricating an item are not working from the latest drawings because they did not know they existed or the document control system failed in some way to deliver the drawings to the people who needed them.

According to Venter (2002), the National Archives of South Africa (NASA) have used until very recently, the US Department of Defence (DoD) 5015.2 standard of functional requirements to ensure that records management (RM) applications meet RM requirements. At present, NASA and the State Information Technology Agency (SITA) are in the process of compiling specifications for Integrated Document Management Systems (IDM) as the required standard for electronic records management in the public sector. Integrated Document Management solutions consist of document management, records management, file/document tracking, integrated imaging and scanning, integrated workflow and integrated search and retrieval functionality. These standards are based on international standards, taking the South African context into account, and can be used as guidelines for companies to select the best EDMS for their needs.

Regardless of the features and sophistication of the EDMS in use, the success of sound document and records management, as well as information sharing and knowledge generation remains dependent upon the commitment of the users. The human element, the employees of an organisation that introduced EDMS, will be considered next.

Knowledge agility and human resource management

The sensitive balance between knowledge management and response ability, that is, knowledge agility, had been mentioned earlier. EDMS is an element of knowledge management. Bender and Fish (2000) assert that knowledge management is a way of working that needs to be imbedded into the work setting, through the organisational strategy, operations design and human resource management. They argue for a change of mind-set from "knowledge = power, so hoard it" to "knowledge = power, so share it and it will multiply" (p. 134). They make a plea for the abandonment of the tradition of knowledge hoarding.

Because people are at the heart of knowledge management (KM), the success thereof depends on an organisation's ability to manage its employees relative to the organisation's knowledge management requirements. It not only requires a change in organisational culture (to informality and openness in knowledge sharing), but profound changes in human resource management $(\mathrm{HRM})$ practices - linking both KM and HRM to the business strategy (Bender \& Fish, 2000; Carter \& Scarbrough, 2001; Farquharson \& Baum, 2002; Hislop, 2003; Mink, Esterhuisen, Mink \& Owen, 1993; Swan, Newell, Scarbrough \& Hislop, 1999; Yahya \& Goh, 2002). The HRM practices these authors mention include appraisals, compensation or rewards strategy, decision-making, education, employee relations, empowerment, the design of jobs, job descriptions, leadership, motivation, organisational development, performance-related pay, psychological contracting, recruitment and selection, teamwork, training and 
development, and trust. Carter and Scarbrough (2001) perceive a symbiotic relationship between human resources management and knowledge management. Hong (1994) cautions about dissonance of human resource practices (versus knowledge management objectives) going undetected. Hislop (2003) draws attention to a disjuncture between the rhetoric and the reality with regard to employment practices and points out indicators such as turnover and job security impacting negatively on KM.

The actual EDMS document status (explicit knowledge) does not take into consideration the tacit knowledge (Hislop, 2003, p. 184; Yahya \& Goh, 2002) "possessed by people (embrained and embodied ...) and ... locked in the human mind". In order to make this knowledge explicit, through either codification or personalisation, there must be a willingness to do so (Carter \& Scarbrough, 2001). The human resource processes should encourage and give recognition tacit knowledge made explicit.

McElroy (2000) points out that three otherwise separate communities of HRM practice are converging, because they share an intrinsically co-dependant view of KM. The communities involved in the meeting of minds are:

- the budding second KM generation,

- the advocates of the learning organisation and systems thinking, and

- the supporters of the applications of complexity theory in business enterprises.

Laszlo and Laszlo (2002), McElroy (2000), and Senge (1990) differentiate between two generations of KM. The first generation focused on information indexing, retrieval and dissemination, usually through technology. The second generation is about sustainable creation, transfer and dissemination of corporate knowledge. Whereas firstgeneration KM concentrated on standards and benchmarks (imitation), the second promotes education and innovation. The second generation KM practitioners complain that firstgeneration KM largely "amounted to little more than a re-hash of yesterday's 'information management' schemes", which "have had little to do, if anything, with knowledge, per se" (McElroy, 2000, p. 199). However, Karamuftuoglu (1999) points out that retrieval, of especially previously unnoticed connections, still has a contribution to make regarding knowledge creation. The first wave of $\mathrm{KM}$ has been about repackaged information capturing, storage, access and retrieval systems sold under the guise of KM. The first generation KM schemes were about the enhancement of day-to-day business process performance. First generation $\mathrm{KM}$ is all about delivering information to support a task. However, Parker (1999) emphasises the importance of KM and the ability to recreate the organisation and its work from scratch after disasters such as the destruction of the Twin Towers on 11 September 2001, New York.

To the 'KM consortium', a think-tank of KM practitioners that holds an unconventional view, the management of knowledge has nothing to do with computer-based repositories. Their view is that "knowledge is the product of natural innovation schemes inherent to all living systems" (McElroy, 2000, p. 197). They postulate that the evolution of new knowledge will be the natural effect of the existence of conditions in which innovation thrives. Their mission is to "crack the secret of innovation" by promoting techniques to enable business "to out-learn, out-innovate, and out-perform their competitors" and to accelerate the production of new knowledge (McElroy, 2000, p. 197).

The advocates of the learning organisation, or organisational learning (OL) practitioners (also known as 'organolearners') differentiate between what individuals know and collective knowledge. It is not just individuals, but also organisations that learn. The tension between the two stimulates innovation and creativity. In this regard, Yahya and Goh (2002) observe that in an individualistic working environment it is not realistic to expect employees to share knowledge willingly and contribute to the work of colleagues. Hislop (2003) cautions that scientists/specialists often regard commitment to a profession more important than commitment to an employer. McElroy (2000) observes that established ways of doing must make way for more efficient ones. The well-known Arie De Gues, quoted by McElroy (2000, p. 199), eloquently made the point "The ability to learn faster than your competitors may be the only sustainable competitive advantage".

It would be a mistake to conclude that organisational learning is merely the accumulative result of individual learning (Ingelgård, Roth, Styhre \& Shani, 2002). Although organisations do not have brains they do have cognitive systems and the corporate memory, which preserves behaviours, norms, values and mental maps. Ingelgard et al. (2002) further point out that there are three perspectives on organisational learning:

- The normative perspective - OL only occurs under a unique set of conditions.

- The developmental perspective - where OL is seen as a late stage of organisational development.

- The capability perspective - presuming that learning is innate to all organisations, and there is no best way for all organisations to learn.

Complexity theory (or more precisely, the science of complexity) is the study of emergent order in what appear to be disorderly systems. "Spirals in whirlpools, funnels in tornadoes, flocks of birds, schools of fish - these are all examples of orderly behavior in systems that are neither centrally planned nor centrally controlled. How and why such coherence emerges in complex systems is a mystery. Nevertheless, understanding its influence on the performance of human organizations could lead to major gains in the conduct of human affairs, especially business" (McElroy, 2000, p. 196). Business enterprises are seen as just another group of complex systems because they display similar behaviours as those found in weather systems or animal populations. Business enterprises are living systems and should therefore be managed accordingly. MacIntosh and MacLean (2001) observed from a complexity theory perspective that system patterns are stable until they reach a critical threshold, the bifurcation point. At this point the stresses make the system unstable and far-from-equilibrium conditions develop, introducing the possibility of radical, qualitative change. At this point the system becomes open to its environment and susceptible to signals which would have had little impact during equilibrium.

The literature review of this article started with a background sketch about the importance of the electronic age and the knowledge-based economy. Thereafter the need for knowledge agility and continuous knowledge development were highlighted. The key aspects of EDMS, as an element of KM, were presented next. The necessity of parity between HRM practices and knowledge followed thereafter. However, the body of literature transcends good HRM practice and includes (a) knowledge evolution as result of innovative conditions; (b) the necessity of developing a learning organisation; and (c) the importance of regarding organisations as complex living systems that should be managed accordingly.

\section{INTERVENTION DESIGN}

In contrast to a conventional article on a research undertaking, this article is about a consulting intervention. The intervention was perceived by the client (a research-type organisation) to improve the human efficacy of their EDMS. Ultimately the intervention spanned a period of nine months and comprised 
three phases. The aim of the first phase involved inculcating custodianship, of the commercialisation and business corporate memory and knowledge repository, among the various levels of management and knowledge workers. The custodianship campaign started with a presentation to the client's management committee to gain their support. During the discussion at the meeting the need for the subsequent phases emanated.

Markham (1994) cautions that a consultant should be aware of the possibility of a four level hierarchy of an intervention; judge at which level it is necessary to start, and guide the client accordingly. Markham's four levels of intervention are:

- Purpose: the aims the client had in mind when agreeing to the intervention.

- Issues: the perceived problem that needed to be addressed and the problem areas that transpired during the duration of the intervention.

- Solutions: the resolution of the perceived and real problems encountered.

- Implementation: the governance and chosen intervention methodology to resolve the problem(s).

Markham (1994) further suggests that a consulting intervention project consists of three major stages, that is, entry, execution and completion. Each stage may consist of a number of steps. The entry stage may comprise:

- Introduction: the consultant needed to familiarise her/himself with the client's processes, procedures, document management culture and divisional structures. Markham (p. 25) calls this unstructured data collection "wallowing".

- Contracting entails both clarification of expectations and attaining commitment.

- Organising which includes the practicalities (the ' $5 \mathrm{WH}$ ' who, when, where, what, why and how) that are key to each level or phase of an intervention, and which should be coupled to the contracting.

The execution stage usually includes data collection, analysis, diagnosis and intervention. However, in reality it very much depends on the nature of the project and the particular level of the phase. The final stage, withdrawal, entails transfer (leaving residual capacity), evaluation (undertaken for quality assurance and credibility purposes), and disengagement.

After a period of wallowing, and in consultation with the EDMS's administrator, it was proposed to and approved by the project/intervention sponsor that user briefing/training at divisional level could proceed. This would be done in order to inculcate custodianship for the commercialisation and business corporate memory and knowledge repository among the various levels of management and knowledge workers. The following phase 1 deliverables were agreed to:

- Facilitation of a 'Commercialisation \& Business EDMS' session at the client's management committee meeting, with the general managers and their respective managers in attendance. This session included:

0 a briefing about the importance of corporate intelligence and electronic knowledge management with regards to the client's transition from being a research and development organisation to being a commercially driven enterprise;

o a work session on the identification of what kinds of documents ought to be captured on the EDMS; and

- a discussion about the custodian role of managers with regards to the commercial \& business corporate memory and knowledge repository.

- Facilitation of divisional level 'Commercialisation and Business $E D M S^{\prime}$ sessions, with the divisional heads and their respective subordinates in attendance. These sessions included:

- a briefing about the importance of corporate intelligence and electronic knowledge management with regards to the client's transition to being a commercially driven enterprise;
- a demonstration of the basic EDMS functions and a suggested flow of information within the client;

0 a work session on the role of staff with regards to building the commercial and business corporate memory and knowledge repository and sensitisation to determining distribution and access requirements for the divisional EDMS person; and

- identification of a departmental representative to serve on an EDMS user group.

During phase 1 two focused PowerPoint presentations were developed, one aimed at the client's management (which was cleared by the project/intervention sponsor prior to the session) and the other aimed at divisional staff. The divisional presentation included key points with regards to knowledge as capital and the management of knowledge as a key asset of the client.

The systems administrator prepared an on-line EDMS demonstration and a concise handout. The demonstration covered aspects such as accessing a document from an e-mail reference, various searches, various view options, copying and printing out of the EDMS, document security/access control versus distribution, version control, document audit trails and tips on the most common problems experienced by users.

The demonstration followed the introductory presentation, whereafter staff members were given the opportunity to ask questions, raise problems and give commentary. The discussions were facilitated in such way that (a) the line authority of the divisional manager concerned; and (b) the responsibility of staff with regard to electronic document management were highlighted. Divisions were further prompted to identify their key business documents that should be captured on the EDMS. The discussions were concluded by the election or appointment of a EDMS representative.

However, there are several electronic systems, each used for a specific purpose, in use at the client. During the presentation to the management committee a policy with regard to where different types of documentation should be stored and a consolidation of electronic systems where possible were requested. The working committee that was formed to address the management committee's request questioned the efficacy of the existing EDMS; and suggested that various alternatives be explored. This resulted in the two additional phases of the intervention:

- The deliverable of phase 2 entailed a comprehensive needs analysis report to the client's Information Technology Steering Committee, which would ultimately take a decision either to remain with the existing EDMS or to implement an alternative EDMS. The needs analysis entailed a survey by means of structured group interviews. It was agreed that the group sessions should ideally include (1) the head of the division, (2) the key knowledge creators and/or key PC users within the division, (3) the Information Technology User Group representative, (4) the identified EDMS User Group representative, (5) the division's current key EDMS input person, (6) the administration person(s) dealing with the division's records, and (7) anybody the manager concerned felt should be present. The consultant further suggested and facilitated, based on the nature of the findings, the insertion of commentary regarding the implications of the perceived needs, from the knowledgeable information scientists. The survey findings, supplemented with counter arguments by information scientists, were presented to the client's Information Technology Steering Committee.

- Phase 3 involved an in-depth comparison of the existing EDMS to another proposed by the working committee, and guidelines from the National Archives of South Africa on selecting an EDMS. 


\section{THE INTERVENTION}

The client, as research and development organisation, not only relies on knowledge as capital for survival in the global economy, but also has a responsibility towards its stakeholders and clients to keep this knowledge in a safe repository.

During 1999 the client recognised the increasing need to manage electronic documents and investigated various EDMS packages. At the time the client's information systems were largely paperbased and all documentation related to a project often not filed consistently, with the result that important information were at times unavailable or lost. Entire files sometimes went missing, because file tracking was not automated and monitored. The client further wanted to improve the productivity of its research staff, as well as cut down on its large volumes of paper usage. The client wanted to ensure that all relevant information generated was retained and easily accessible to those who have the applicable access rights.

During 2 - 6 August 1999 the then local EDMS supplier carried out various functional specification meetings at the client and customised the software accordingly. From the functional specification meetings held, it became evident that there was no structure within the client with regard to saving electronic documentation, and that each division or individual saved their documentation in their own peculiar format of choice. The supplier expressed their concern in this regard and pointed out that there would need to be strong discipline from the users to input the necessary information.

Since the inception of the EDMS at the client, the aim had been to capture the most important technical documentation (mostly reports to clients). However, with a rapidly decreasing research funding, the client had had to generate an increasing income from business ventures. The result was a drastic increase in business-related documentation, which was not yet captured on the EDMS. The intervention would serve to impress on managers and staff, not only the importance of EDMS, but also the importance of capturing all documentation - including work-in-progress and business documents - for commercial viability.

A substantial body of documents (about 4200) had been saved to the EDMS over the two and a half years prior to the intervention. However, it appears as if document management at the client depend largely on the insistence (or lack thereof) of the secretaries or divisional administration officers, and also on the Information \& Communications division, which is responsible for the administration and maintenance of the system. Executive management through to research and development staff, as the knowledge leaders, were for the most part apathetic about the idea of electronic document management. For an EDMS to succeed at the client, this group had to be made aware of the role an EDMS could play in the productivity of the organisation as a whole.

The client makes use of software that, among others, monitors the user activity on the Intranet. The software identifies each user based on the network user identification. Figure 2 indicates, for the period April 2002 to January 2003, (a) the number of unique users who had accessed the EDMS, (b) which of these users visited once, and (c) which of these users visited more than once. During the three-month period (April - June 2002) prior to the intervention, an average of 20.7 unique users had accessed the EDMS, of which 13.7 accessed once and only 7 more than once. This does not even account for the number of divisional heads. The number of unique users who had accessed the EDMS equates to only $15.1 \%$ of the $\mathrm{n}=137$ knowledge workers who could possibly have accessed the EDMS. Only 5.1\% had accessed the EDMS more than once per month.
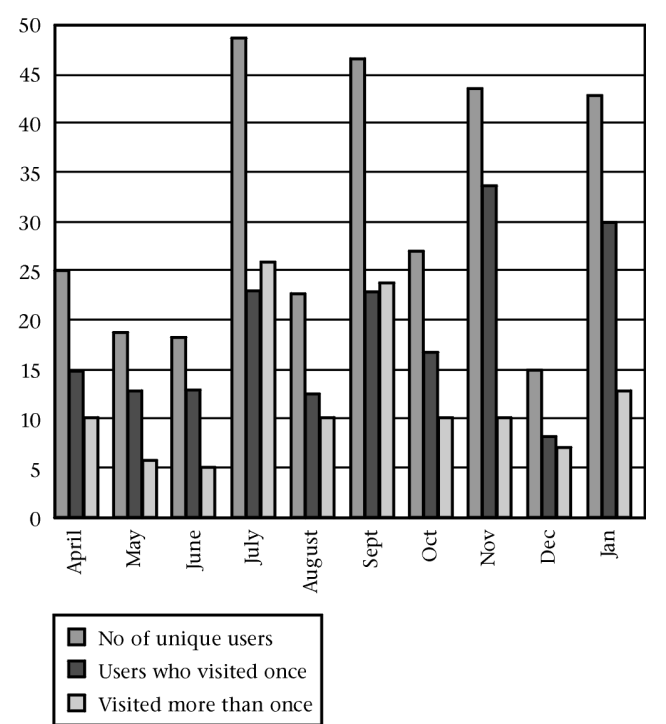

Figure 2: The EDMS user statistics for the period April 2002 to January 2003

The analysis of the usage statistics clearly showed that the EDMS was not being used to its full potential. During the management committee and divisional presentations, the following reasons emerged:

- Confusion about which documents should go to which system.

- Lack of management motivation to use the system.

- Apathy towards a system that staff had read-only access to. The ideal would be for all staff to have full access (create, store and edit).

- Bottlenecks created by numerous documents sent to divisional secretary or administrative person, with full access, for inclusion in the EDMS. The client's document culture had undergone a change from secretaries typing most documents to research and development staff creating their own documents.

- Unfamiliarity with the system. Since usage was not enforced staff were not motivated to familiarise themselves with the system.

These problems were partly addressed during phase 1 (a presentation about the benefits and importance of EDMS and an on-line demonstration of the basic functions). It was clear that a further phase would be necessary, which would include a working committee to create a document management policy and a EDMS user group that would communicate problems and needs to the systems administrator. It also became clear that the installation of facility that would enable users to double click on an e-mail reference to open a document, was a top priority. Without it users had to copy the extract document number from the link name, open EDMS and then do a search on the document number. This was experienced as unnecessarily cumbersome and time consuming.

The immediate outcome of phase 1 was a dramatic improvement in the EDMS usage statistics from September 2002 (see Figure 2). The anomalous sudden increase in July 2002 can be ascribed to (a) increased document retrieval in preparation for an ISO 9001 accreditation which took place in this month, and (b) the systems administrator frequently logging in to update the EDMS user manual and to put together the demonstration. The same observation (b) is made about the bar reflecting unique users visited more than once during September 2002, when the systems administrator repeatedly logged in as an EDMS user to do the live demonstrations. A comparison of the statistics of the periods before the intervention is reflected in Table 2 . 
TABLE 2

COMPARISON OF USER STATISTICS, BEFORE AND AFTER THE INTERVENTION

\begin{tabular}{lccc}
\hline & $\begin{array}{c}\text { Average for April } \\
\text { to June 2002 }\end{array}$ & $\begin{array}{c}\text { Average for Sept } \\
\text { 2002 to Jan 2003 }\end{array}$ & $\begin{array}{c}\text { Percentage } \\
\text { improvement }\end{array}$ \\
\hline Number of unique users & 20.7 & 35.2 & $70.3 \%$ \\
Users who visited once & 13.7 & 22.4 & $63.9 \%$ \\
Visited more than once & 7.0 & 12.8 & $82.9 \%$ \\
\hline
\end{tabular}

A number of points were raised during the various divisional presentations of phase 1 :

- An urgent plea for a firm policy on document management which would simplify the lives of staff and prevent duplication, including policy guidelines on the management of e-mails.

- A need was expressed for an overarching web interface facility that would enable staff to search and access all the various knowledge systems at the client through a single point of entry.

- A strong need was conveyed for all staff to at least be able to view the profile of documents even if they could not access the document itself, because valuable information may be withheld from staff if they are not aware of the existence of particular documents. Individual staff members could then arrange access to confidential documents if needed. The systems administrator immediately changed the default security of new documents accordingly, and promised to amend the security of existing documents.

- The environmental impact of using less paper was mentioned.

- During two sessions enquiries were made about documentation dated prior to the inception of the EDMS. It was explained that documents can either be imported (if available in electronic format), scanned in, or paper profiled and referenced to their existing physical location.

- Frustration was voiced about the vagueness of the subject lines of e-mails announcing documents on the EDMS. The systems administrator undertook to 'educate' full-access users to identify a document clearly.

- A proposal was made that scientific papers obtained through Interlibrary Loans should be saved on the EDMS for internal use. The copyright implications, however, need to be considered and clarified.

- Due to the high turnover of secretaries, consideration should be given to make a divisional administrative staff member the full-access user.

- Registry often assigns insignificant file names to scanned documents. It is foreseen that this will result in difficulty with searches. Registry should remedy the situation.

- At one session the view was strongly expressed that the client does not need an sophisticated EDMS like the existing one. The point was made that there were much cheaper alternatives available. It is believed that an appropriate directory structure, a rigid filename convention and a suitable search engine are all that is needed. However, such a system would not constitute document management, and would necessitate enforcing policies regarding the naming and storage of documents.

The EDMS access is controlled on an operating system (Windows NT) level. However, the NT accounts did not always correspond to the EDMS individual user and group accounts. The reason for this was that the system administrator was not always informed of changes to the NT accounts due to staff movements. During the session with the Human Resources division, it became evident that they experienced equal frustration with keeping track of staff movements. A firm standard operating procedure that would ensure that Human Resources, Information Technology, Finance and the EDMS' administrator are kept up to date with regard to staff movements is considered essential.

The phase 2 needs analysis survey involved 39 staff members from 11 different divisions of the client. Participants were asked to rate various identified features of electronic document management in general and to indicate if the feature is considered (a) essential, (b) important, (c) nice to have, or (d) irrelevant. With regard to some features additional information was collected. Any commentary volunteered was further recorded.

\begin{tabular}{|c|c|c|c|c|}
\hline 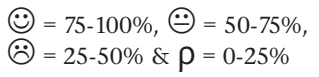 & Essential & Important & $\begin{array}{l}\text { Nice to } \\
\text { have }\end{array}$ & Irrelevant \\
\hline Management of documents & $+:)$ & 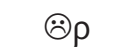 & $: \rho p$ & $: 0$ \\
\hline Collaboration among users & : & $: \rho$ & $\theta \rho$ & $\rho$ \\
\hline Saving of documents & ;: & & & \\
\hline Importation of documents & $+:)$ & $\therefore \rho$ & $:$ & \\
\hline $\begin{array}{l}\text { Relationships between } \\
\text { documents }\end{array}$ & ;) & $\rho$ & $\rho$ & \\
\hline Control of documents & $+;)$ & $\rho$ & $\rho$ & $\rho$ \\
\hline $\begin{array}{l}\text { System \& document } \\
\text { security }\end{array}$ & $+:)$ & $\rho$ & 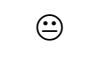 & \\
\hline Search functinality & ;) $\rho$ & $: \bullet$ & $\dot{\theta} \rho$ & \\
\hline $\begin{array}{l}\text { Integration with } \\
\text { applications }\end{array}$ & ;) $\rho$ & 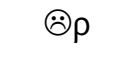 & $: \rho$ & $\rho$ \\
\hline Archiving & : & : & $\rho$ & \\
\hline Other EDMS features & $\otimes p$ & 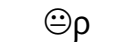 & $\rho$ & $\rho$ \\
\hline
\end{tabular}

Figure 3: Summary of the needs-analysis survey about electronic document management

Figure 3 represents a summary of the survey findings. Management of documents included six subsidiary items, that is, management of standard types of electronic documents; management of scanned images; management of paper documents; capturing of information about documents (metadata); multiple authors; and distinguishing between typist and author. The ratings of the subsidiary items were averaged. That is the reason for the range ratings. The item collaboration among users included two subsidiary items, that is, sharing documents with collaborating co-authors and sharing without breaching security. Importation of documents included both existing documents and mass importation. Control of documents included four subsidiary items, that is, capturing the audit trail or history of each document; version control of documents; standardised entry of metadata; and prevention unauthorised deletion of documents. System and document security included four subsidiary items, that is, controlled access to EDMS; document-level access control for confidentiality; assignment of different levels of security to specified user groups; and the ability to assign e.g. open access to a final document but only access to the author(s) of the draft versions.

Search functionality included eight subsidiary items, that is, ease of searching; ability to do advanced searching; ability to do searches on metadata; ability to search the contents of documents; ranking of search results according to relevancy; highlighting of search terms in retrieved documents; saving of regular searches; and the ability of printing search results. Integration with other applications included four subsidiary 
items, that is, EDMS must integrate with commonly used applications within the client organisation; ability to save to the EDMS from within a commonly used application; ability to quick view documents; and a viewer enabling the viewing of documents created in applications that are not installed on the user's PC. The item other EDMS features included accessibility to all staff; working in off-line mode; when the network goes down continue working without losing modifications; flexibility to cater for changing needs; and the ability to see the history of the path a document followed. A comprehensive report in this regard was presented to the client.

At the client the principal author of a document controls the input and is responsible for collating, editing, and ensuring that the tables and figures are correctly numbered. In extreme situations an appendix is stuck in at the back. The principal author signs off the document and takes responsibility for the content. They do not see collaboration as a function of EDMS. There is a concern that it would slow the process down. The general collaboration process is illustrated in Figure 4. The process might go backwards and forwards multiple times. One participant labelled the process as diabolical: contributors send notes to each other, e-mail one another, meet each other - the survey participant concluded that it is important to collaborate. Another participant stated "I hate the current process, it is so clumsy." In contrast to these two views some other participants were satisfied that MS Word's 'track changes' worked well for their purposes. However, another participant viewed an EDMS process as a recipe for disaster.

\begin{tabular}{c} 
Draft written \\
Sent (via e-mail) to contributors for perusal or made available on shared \\
directory. \\
Commentary made \\
Returned to main author for integration and consolidation \\
\hline
\end{tabular}

Figure 4: Illustration of the document collaboration process

Due to the confidential nature of phase 3 it is regrettably not possible to publish the results, suffice to state that the client's existing EDMS is the superior product. The saving and prior investment would not have warranted the loss of functionality.

The report produced in phase 3 , together with the needs analysis report (phase 2), were tabled at the meeting of the client's Information Technology Steering Committee held in February 2003. At this meeting, it was decided (a) to phase out the existing EDMS (the system was considered too expensive, especially in the light of the hardware upgrades that would be needed to give full access to the system to all staff members), (b) not replace the EDMS with another (due to important points raised in the comparison), and (c) disregarding the warnings about 'storage \& retrieval' versus EDMS, to create a proprietary system based on Windows 2000. It had been envisaged that this system would be functional by July 2003. A final warning about the possible legal implications of disregarding 'best practice' guidelines from the National Archives of South Africa, in particular those pertaining to version control, audit trails, metadata, and selection lists to capture metadata had been the last step in this intervention.

\section{DISCUSSION}

The initial brief of this intervention was limited to improving the efficacy of the EDMS in use. Markham (1994) cautions that if an intervention starts at level 1 ('purpose') it is not easy to predict what will happen. Work at subsequent levels depends on what had transpired at preceding levels. He recommends an iterative process, breaking the overall intervention into separate phases. The consultant realised the utmost importance of clarifying and contracting at each phase of a consulting intervention, as it unfolds, and if any new expectancies or complexities arise, that the brief is again clarified and contracted. It is essential that respective understandings are reduced to a written agreement. An undertaking of this nature is a careful balancing act of project management principles; consulting principles; know-how related to the nature of the consulting intervention; an arsenal of people management skills; and a sixth sense pertaining to organisational politics.

The phase 2 needs analysis survey uncovered a prevailing 'storage-and-retrieval' paradigm at the client, as well as an ignorance of what document management entails and a lack of management input. It also became clear that 'buy-in' would only be achieved if all staff members had full access to the EDMS, both to access and to store, edit and share information.

From this intervention it became evident that the client had to undertake an extensive change management intervention to shift the paradigms of especially, but not only, their research and development staff. The client's human resource management systems must be transformed to support a knowledge management paradigm. It is evident that the majority of the staff perceives an EDMS to be a replacement of the former paper registry (storage facility). The EDMS is not perceived as a way to store, manage and control the current intellectual capital. Consequently, the value of the electronic sharing of documented knowledge in pursuing a learning organisation is not perceived.

This article attempted to illustrate that if an organisation introduces EDMS without doing the required groundwork, EDMS alone would not secure the corporate memory. Managing the knowledge capital of an organisation as strategic intelligence requires a comprehensive organisation intervention. This includes the simultaneous review of human resource management policies and procedures in order to create a knowledge management culture, which would be conducive to knowledge agility.

\section{REFERENCES}

Bender, S. \& Fish, A. (2000). The transfer of knowledge and the retention of expertise. Journal of knowledge management, 4 (2), 125-137.

Carter, C. \& Scarbrough, H. (2001). Towards a second generation of KM? The people management challenge. Education \& Training, 43 (4), 215-224.

Dove, R. (1999). Agility $=$ knowledge management + response ability. Paradigm shift international. Retrieved December 09, 2002 http://www.parshift. com/Essay/essay051.htm.

Farquharson, L. \& Baum, T. (2002). Enacting organisational change programmes: a centre stage role for HRM? International Journal of Contemporary Hospitality Management, 14 (5), 243-250.

Hislop, D. (2003). Linking human resource management and knowledge management via commitment, a review and research agenda. Employee Relations, 25 (2), 182-202.

Hong, J-C. (1994). Technology transfer and human resource development. Industrial and Commercial Training, 26 (11), 17 21 . 
Ingelgård, A., Roth, J., Styhre, A. \& Shani, A.B. (2002). Dynamic learning capability and actionable knowledge creation. The Learning Organization: An International Journal, 9 (2), 65-77.

Karamuftuoglu, M. (1999). Information retrieval and the perpetual innovation economy. Aslib Proceedings: new information perspectives, 51 (4), 99-108.

Kraak, A. (2000). Changing modes, new knowledge production and its implications for higher education in South Africa. Pretoria: Human Sciences Research Council.

Laszlo, K.C. \& Laszlo, A. (2002). Evolving knowledge for development: the role of knowledge management in a changing world. Journal of Knowledge Management, 6 (4), 400-412.

MacIntosh, R. \& MacLean, D. (2001). Conditioned emergence: researching change and changing research. International Journal of Operations \& Production Management, 21 (10), 1343-1357.

Markham, C. (1994). The top consultant, developing your skills for greater effectiveness. Revised edition. London: Kogan Page.

McElroy, M.W. (2000). Integrating complexity theory, knowledge management and organisational learning. Journal of Knowledge Management, 4 (3), 195-203.

Megill, K.A. (1997). The corporate memory: information management in the electronic age. West Sussex: Bowker-Saur.

Mehra, K. (2001). Two aspects of knowledge dynamics: knowledge as capital or as infrastructure. National Institute of Science and Development Studies, India. Retrieved
December 09, 2002 from www.delft2001.tudelft.nl/ abstract\%20files/ abstract1008.doc.

Meredith, S. \& Francis, D. (2000). Journey towards agility: the agile wheel explored. The TQM Magazini, 12 (2), 137-143.

Mink, O.G., Esterhuisen, P.W., Mink, B.P. \& Owen, K. Q. (1993). Change at work. San Francisco, Calif.: Jossey-Bass.

Parker, E. (1999). Managing your organisation's records. London: Library Association Publishing.

Senge, P. (1990). The fifth discipline: the art and practice of the learning organisation. New York, NY: Currency Doubleday.

Swan, J., Newell, S., Scarbrough, H. \& Hislop, D. (1999) Knowledge management and innovation: networks and networking. Journal of Knowledge Management, 3 (4), 262-275

Venter, L. (2002). Strategy for the management of electronic records in the public sector: building strategic alliances. Presented at the Electronic Records Workshop, 21-22 February 2002, UNISA, Pretoria.

Vernadat, F.B. (1999). Research agenda for agile manufacturing. International Journal of Agile Management Systems, 1 (1) 37-40.

White, A. (2001). New technologies in document management. In the Minex conference. http://www.debretts.com.au/ minex/White.html.

Yahya, S. \& Goh, W-K. (2002). Managing human resources toward achieving knowledge management. Journal of Knowledge Management, 6 (5), 457-468. 